SECTION 31. Economic research, finance, innovation.

\author{
Vasilyeva Valeria Alekseevna \\ Master of economy \\ The deputy chief of information and library department \\ Russian Presidential Academy of National Economy \\ and Public Adminisrtation, Russia \\ email: vavasilyeva@gmail.com
}

\title{
THE APPLICATION OF BIBLIOMETRIC METHODS FOR DETECTION OF NEW TRENDS IN THE DEVELOPMENT OF INTEREST IN GASIFICATION OF BIOMASS
}

\begin{abstract}
Based on bibliometric database are explored publications on the gasification of biomass using science-metric indicators. At the analysis of publication are taken into account temporal changea. The regional dimention, the dynamics of interest to the topic. Russian and foreign indicators are compared, draws the conclusions about the validity using of bibliomtrics methods for determine the relevance of the scientific direction .

Key words: bibliometry, bibliometric analysis, bibliometric researches gasification of biomass.

\section{ПРИМЕНЕНИЕ БИБЛИОМЕТРИЧЕСКИХ МЕТОДОВ ДЛЯ ВЫЯВЛЕНИЯ НОВЕЙШИХ ТЕНДЕНЦИЙ В РАЗВИТИИ ИНТЕРЕСА К ГАЗИФИКАЦИИ БИОМАСС}

\begin{abstract}
Аннотация: На основе библиометрических баз данных предпринимается попытка исследования публикаций по проблеме газификации биомасс с помощьью наукометрических инструментов. При анализе массива публикаций учитываются временные изменения, региональный аспект, динамика интереса $к$ теме. Сравниваются российские и зарубежные показатели, делаются выводы о правомерности использования методов библиометрии для определения актуальности научного направления.
\end{abstract}

Ключевые слова: библиометрия, библиометрический анализ, газификация биомасс.

В современном обществе, когда стоимость научных исследований и степень влияния достигаемых результатов на социально-экономические процессы возрастают, мониторинг и анализ научно-информационных потоков становятся основным средством изучения сотрудничества в любой научной области. Именно библиометрические базы данных позволяют детально исследовать статистику публикаций по любой отрасли знаний [9] . Массив научных публикаций предстает как отражение интереса к исследуемой области, величина и частота цитирования показывает уровень взаимодействия специалистов. Анализ этого массива методами наукометрических исследований позволяет дать объективную картину развития научного направления, оценить его актуальность и потенциальные возможности $[1,8]$.

В последние время во многих странах возрос интерес к тем или иным альтернативным технологиям получения энергии, однако эта тема интересовала ученых достаточно давно. Достаточно полно массив публикаций, начиная с XIX века, отражен в библиографическом списке В.В.Копытова [5], где, в частности приведена динамика патентов, зарегистрированных в России, за 100 лет, показывающая «...после периодических пиков в 20 -е, 30 -е и 40 -е годы прошлого века и провала в 50 -е ... 70-е 
годы имел место быть краткий по времени всплеск интереса к этой тематики в начале 80-х годов... И, наконец, ярко выраженный взлёт в середине первого десятилетия XXIго века...» (рис. 1). В ряде публикаций делается вывод, о том что «газификация - это технология «смутного времени», когда приоритетом становится не эффективность варианта решения, обеспечивающего выживаемость, а само физическое выживание отдельного человека, его семьи и бизнеса». [3]

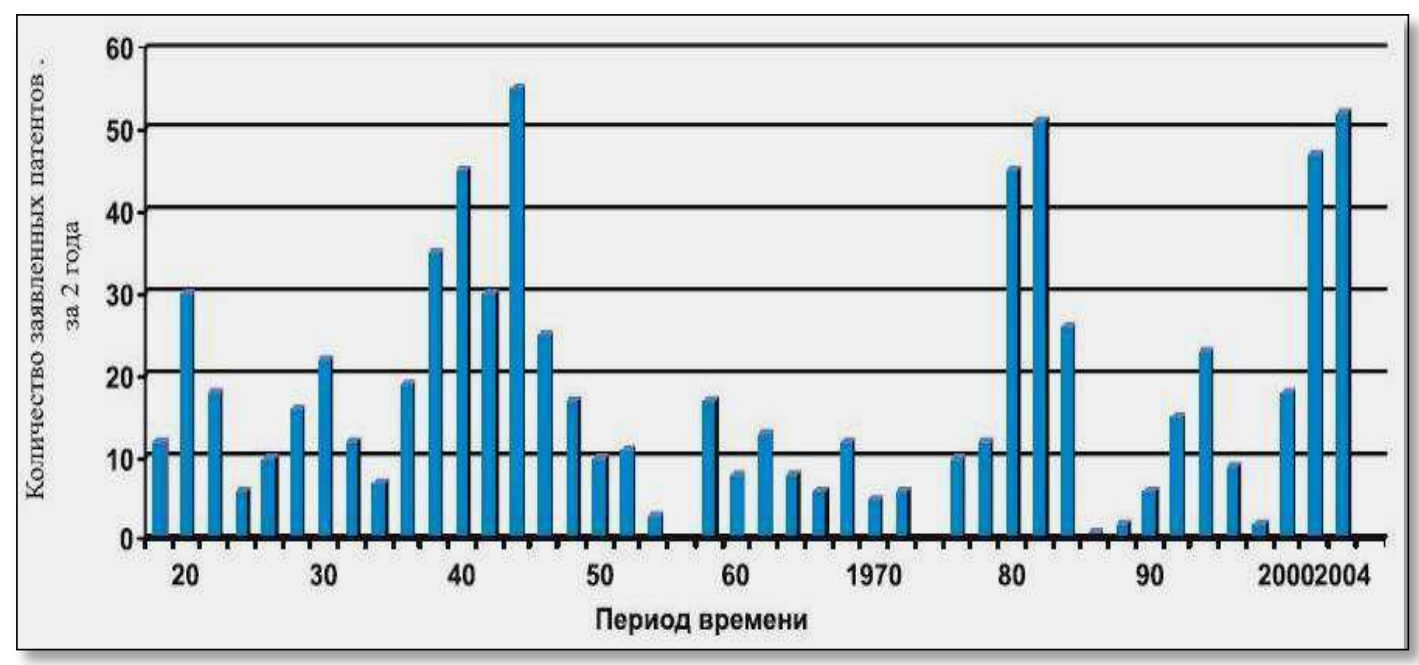

Рисунок 1 - Динамика патентов в России.

Автор данной статьи поставил перед собой задачу количественно выявить и проанализировать динамику «интереса» к вопросам газификации биомасс с помощью библиометрических инструментов путем анализа научных публикаций, а не только патентов, Использование статистического подхода позволяет решать задачи динамики числа открытий, журналов, учёных, использование метода подсчета числа публикаций даёт картину распределения публикаций по странам, языкам и типам издания, а исследование научного цитирования дает возможность изучить коммуникацию в профессиональном сообществе. [10] Конечно, неполнота этих данных очевидна, поскольку немало идей черпается в неформальном общении ученых, на конференциях, симпозиумах, при личном контакте специалистов. $[4,8]$

В ходе данного исследования был применен метод подсчета числа публикаций (распределение по годам, выборочно регионам и странам), а в качестве источников предоставления данных - база данных Scopus компании Elsevier c удобным библиометрическим инструментарием для исследования англоязычных публикаций, и национальная информационно-аналитическая система «Российский индекс научного цитирования (РИНЦ) на платформе elibrary.ru для изучения русскоязычных и изданных в России публикаций. Также была использована Электронная библиотека диссертаций Российской государственной библиотеки, содержащая авторефераты и диссертации российских ученых. Чтобы избежать дублирования при подсчете публикаций и цитирований, данные из Web of Science не учитывались, так же, как и публичные источники информации - Google Scholar и др.

Для обеспечения сопоставимости результатов были заданы одинаковые поисковые условия - словосочетание «газификация биомассы» (для англоязычных публикаций - gasification biomass) с применением логических операторов «и» (\&) и усечение формы слова *. В сравнении участвовали страны ЕС (вместе и по отдельности), США и Канада, а также Китай, который в последние десятилетия по масштабам исследований прочно занял первые позиции. 
Прежде всего рассмотрим, в каком регионе наблюдается самое большое в количественном отношении, число публикаций по теме технологии газификации древесины и шире - биомассы. Явный приоритет за Соединенными Штатами, за ними следует Китай, Япония и только на четвертом месте Германия (рис.2) Следует заметить, что в последние десятилетия китайские ученые во многих областях знаний сделали мощный рывок и переместились в первые места по числу публикаций в англоязычных изданиях. То, что и в такой, достаточно узкой теме, как газификация биомассы, Китай вышел на второе место в мире, говорит о большой востребованности исследований подобного рода в этом регионе.

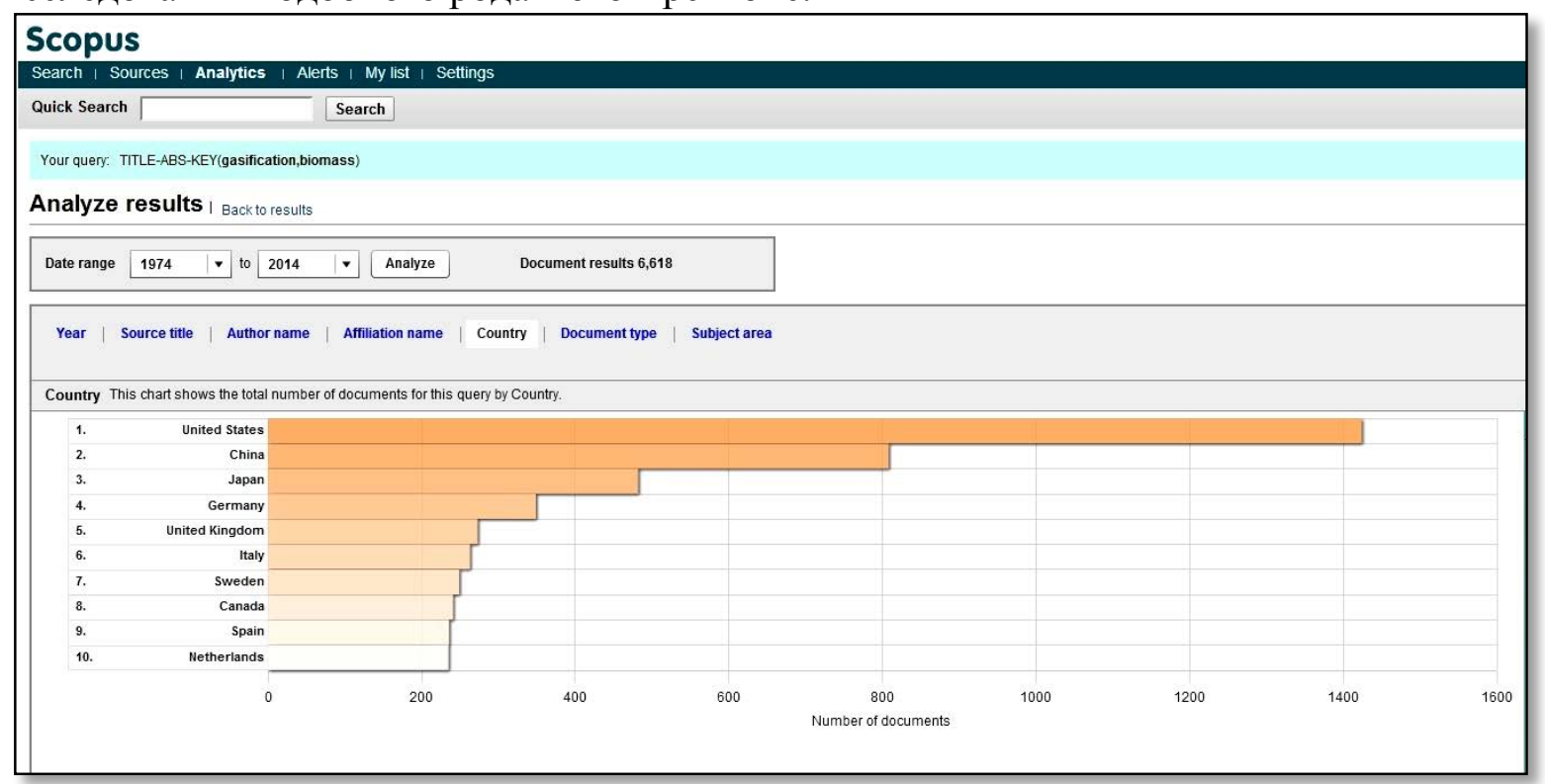

Рисунок 2 - Страны с наибольшим количеством публикаций.

Из европейских государств самой активной по исследованием была и остается Германия. За ней следуют Великобритания и Италия (рис. 3.)

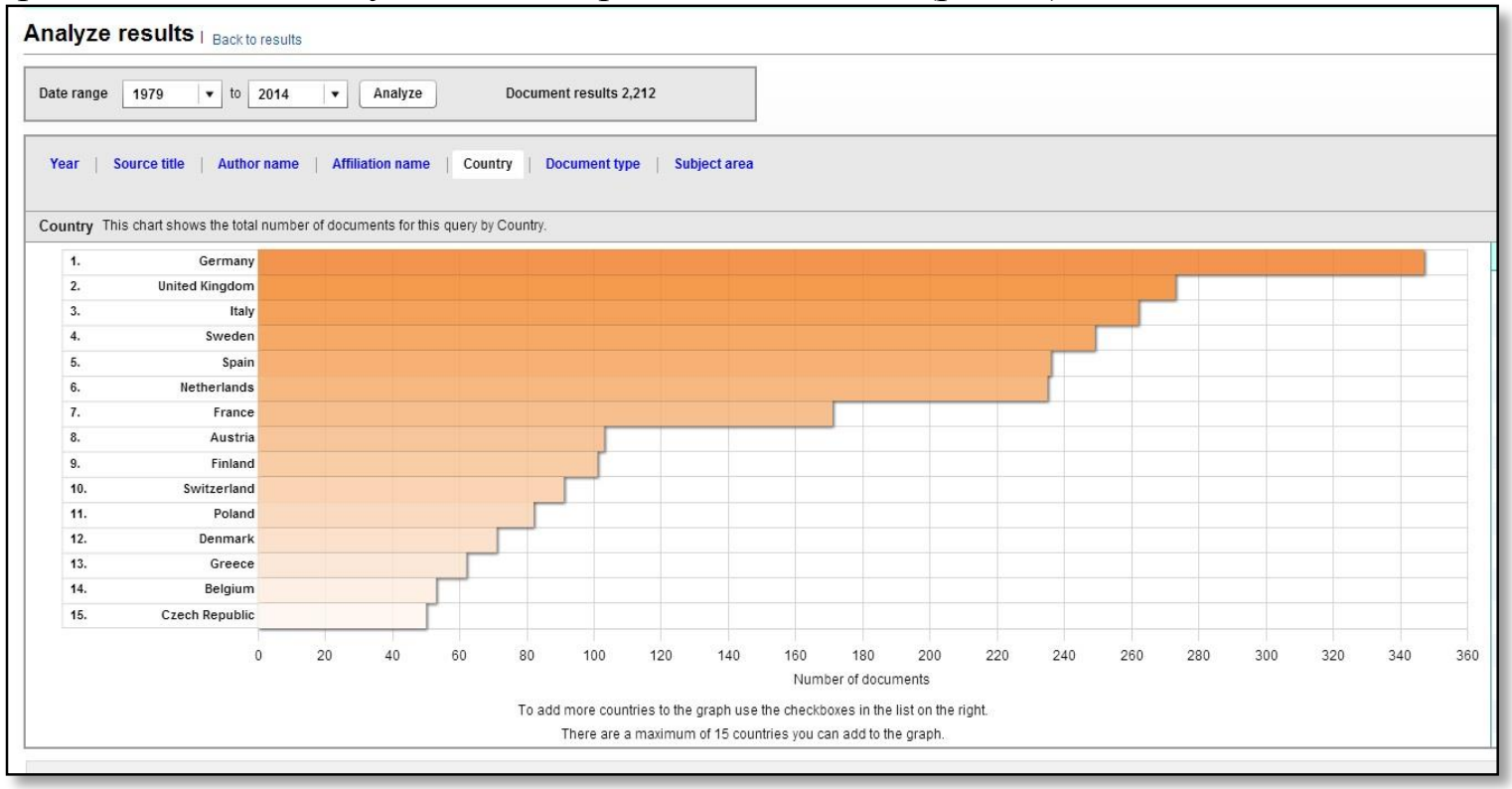

Рисунок 3 - Страны ЕС с наибольшим количеством публикаций.

Наибольшее число опубликованных исследований по исследуемой тематике принадлежит Национальной Лаборатории возобновляемых источников энергии (США). 
Можно было предположить, что такая общая динамика (резкое увеличение общего числа публикаций к началу XXI века) связана в основном с тем, что возросло общее количество публикаций в электронном виде, как и их индексация в библиометрических базах данных и, естественно, этот фактор нельзя сбрасывать со счетов [6]. Однако, то, что в последние годы изменилась структура интереса к проблемам газификации биомасс как к альтернативному источнику энергии, показывает простое сравнение графиков публикаций в БД Scopus:

Публикации по теме «Нефтяная промышленность» (рис. 4):

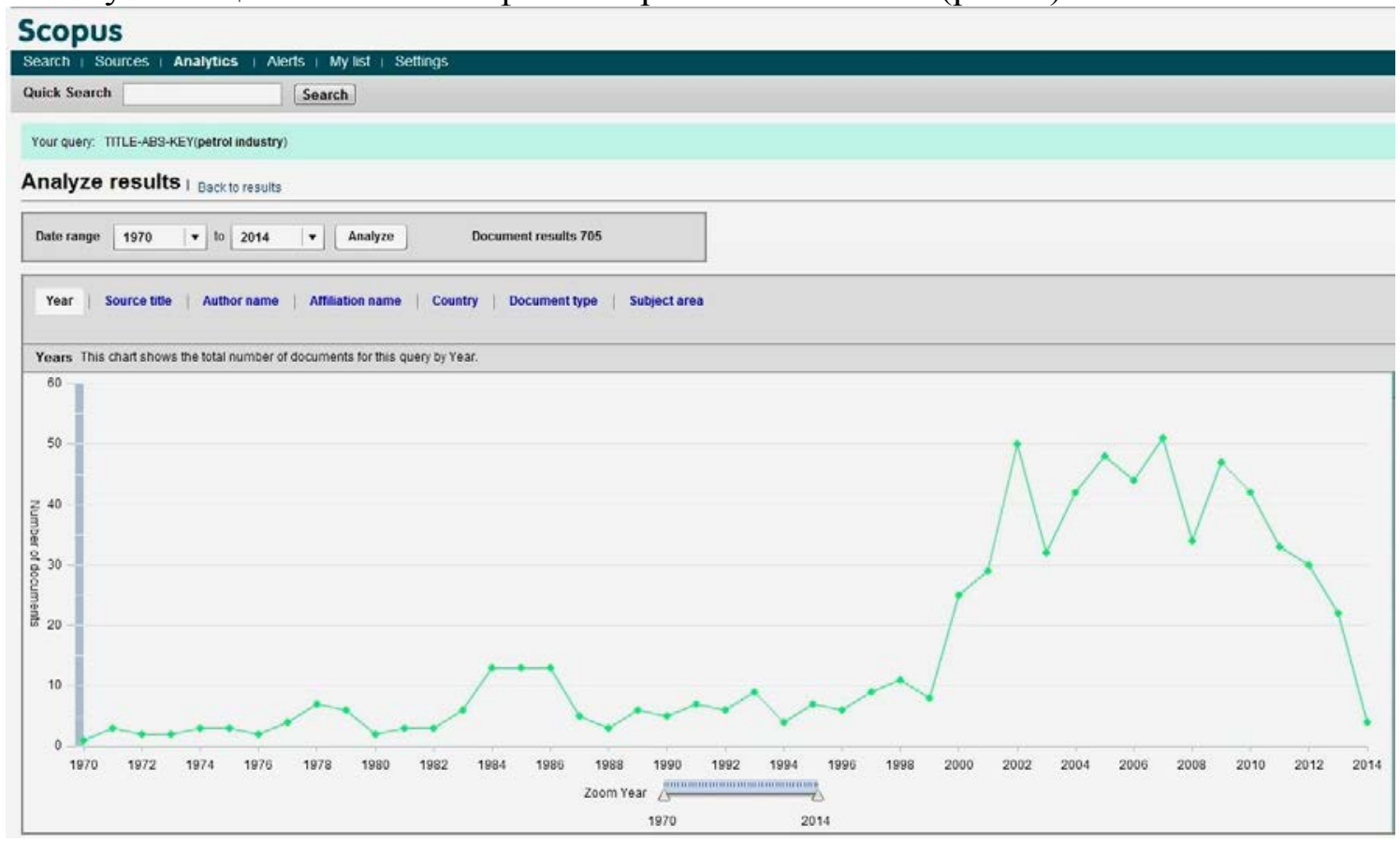

Рисунок 4 - Динамика количества публикаций по теме «Нефтяная промышленность».

Динамика неровная, хотя и возрастающая по общему количеству публикаций, с периодическими «провалами» и «всплесками» активности. В сравнение - публикации по теме «Газификация биомасс» (рис.5), где наблюдается однозначный скачок интереса в последние годы и практически полное отсутствие такового до начала 2000-х годов:

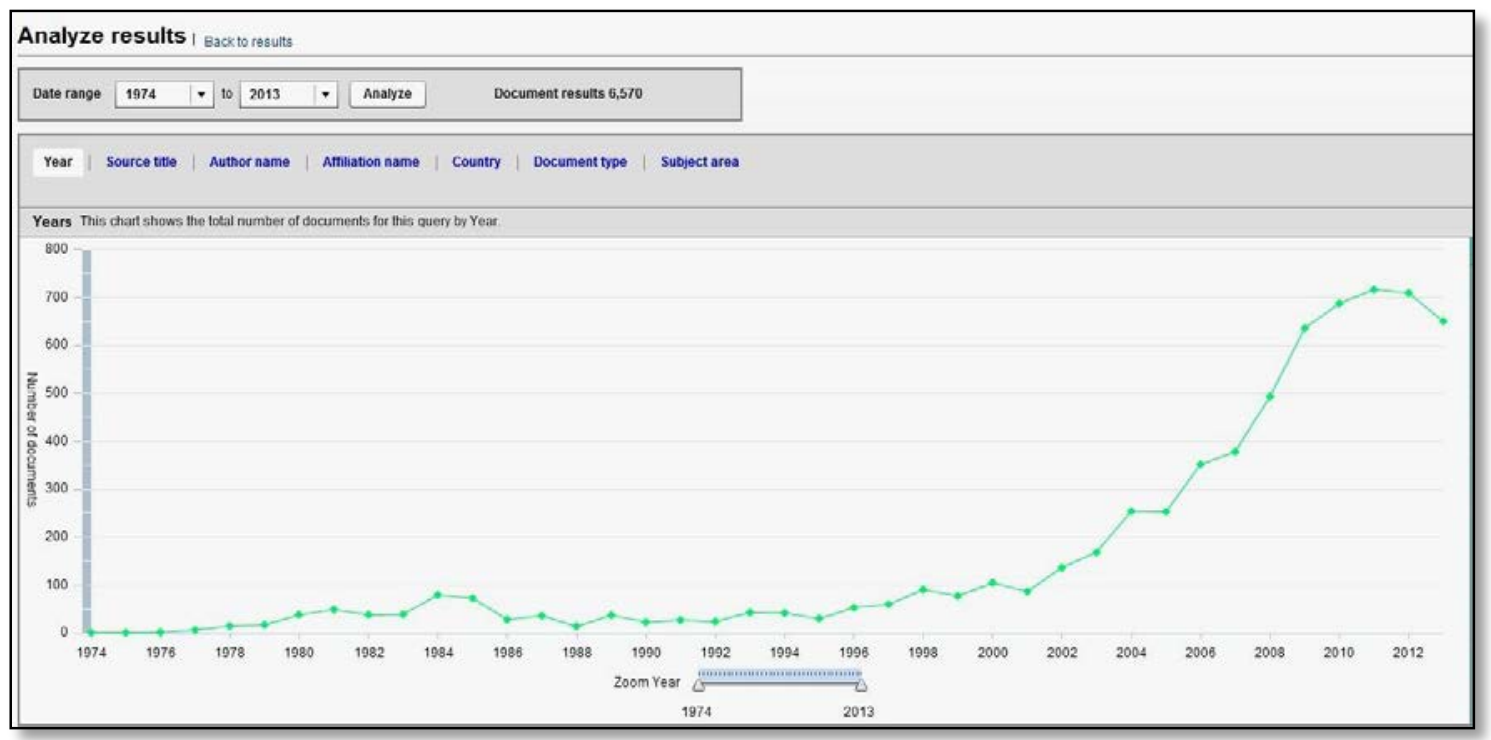

Рисунок 5 - Динамика числа публикаций по теме «Газификация биомасс». 
Та же ситуация и с цитированием публикаций по этим темам. На основании этих графиков можно сделать вывод, что фактор всеобщего увеличения электронных публикаций ученых и расширения возможности представления их научной общественности хоть и должен учитываться, но не может служить решающим при анализе активности исследователей в той или иной области.

На рис. 6. представлены все публикации стран Европейского Союза (все страны вместе) и США и Канады, начиная с 1975 года (когда вообще не было ни одной публикации) до 2013 г., учитывая, что не все периодические издания, вышедшие в 2013 году, могли быть проиндексированы на момент составления запросов.

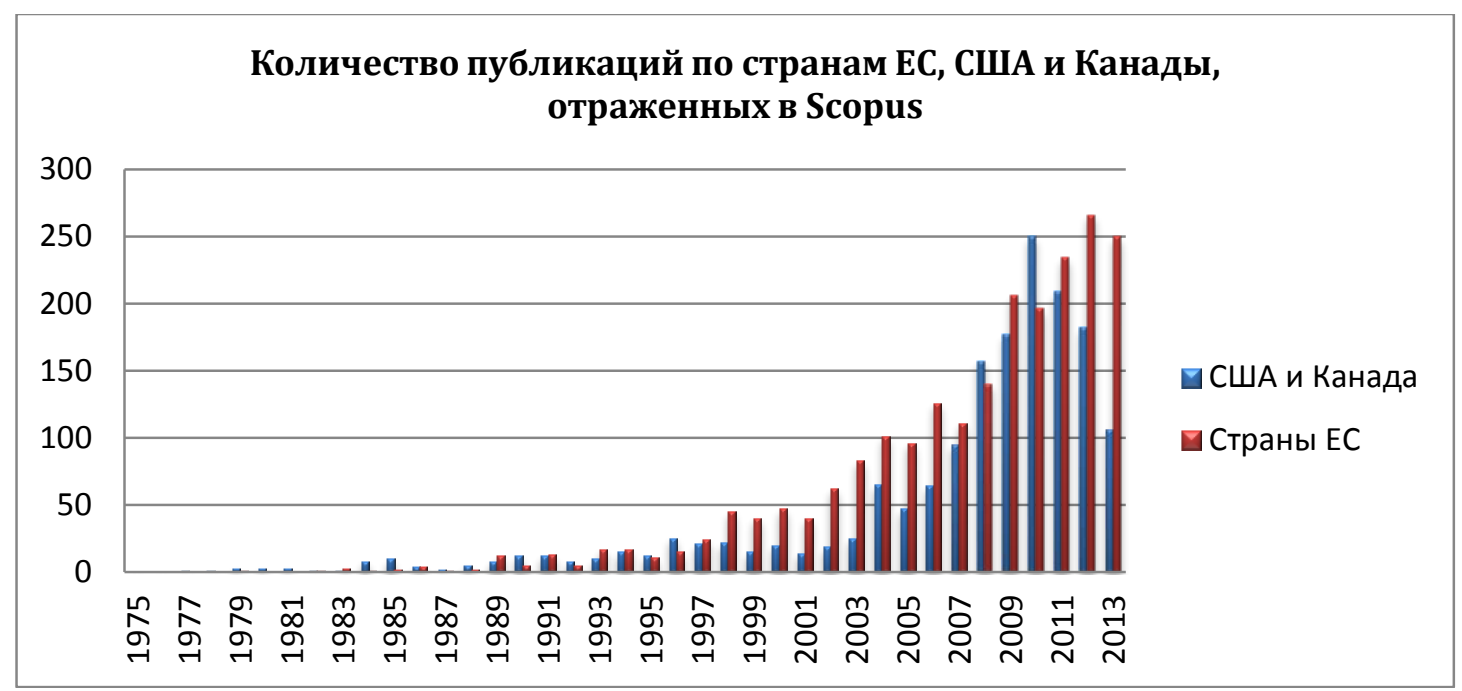

Рисунок 6 - Динамика публикаций по двум регионам.

На основании данного графика можно сделать вывод о неравномерно нарастающем интересе к исследованиям вопросов газификации биомассы на разных континентах. После 2009 года в США и Канаде спрос на подобные разработки относительно снизился, возможно, вследствие развития технологии добычи газа из сланцевых пород («сланцевая революция») и иных способов получения энергии именно в начале XXI века [2]. В Европейских государствах, напротив, рост интереса к газификации биомассы стабилен, количественные показатели по публикациям превосходят США и Канаду, и идут по нарастающей.

Русскоязычные публикации в БД Scopus представлены лишь единичными статьями, поэтому исследования по теме «газификация биомасс» берутся из системы РИНЦ (рис. 7): 


\section{Количество публикаций и цитирований, отраженных в РИНЦ}

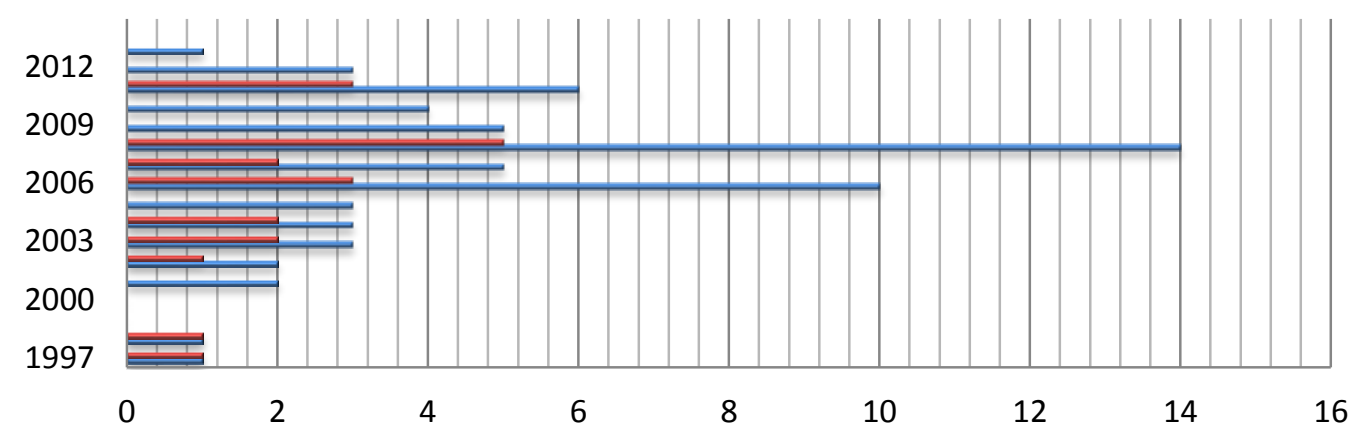

\begin{tabular}{|l|l|l|l|l|l|l|l|l|l|l|l|l|l|l|l|l|l|l|l|l|l|}
\hline 1997 & 1998 & 1999 & 2000 & 2001 & 2002 & 2003 & 2004 & 2005 & 2006 & 2007 & 2008 & 2009 & 2010 & 2011 & 2012 & 2013 & 2014 \\
\hline
\end{tabular}

\begin{tabular}{|l|l|l|l|l|l|l|l|l|l|l|l|l|l|l|l|l|l|l|}
\hline - Цитирования & 1 & 1 & 0 & 0 & 0 & 1 & 2 & 2 & 0 & 3 & 2 & 5 & 0 & 0 & 3 & 0 & 0 & \\
\hline - Публикации & 1 & 1 & 0 & 0 & 2 & 2 & 3 & 3 & 3 & 10 & 5 & 14 & 5 & 4 & 6 & 3 & 1 & \\
\hline
\end{tabular}

\section{Рисунок 7 - Российские публикации.}

При обращении к аналитической системе РИНЦ важно учитывать, что глубина архивов изданий, представленных в системе, охватывает, за редким исключением, выпуски не ранее 90-х годов и здесь мы можем анализировать только последнее десятилетие. Интересен в данном случае «всплеск» публикаций в 2008 году, когда случился мировой кризис. Не есть ли это реакция на возможные надвигающиеся проблемы с ресурсами и желанием «подстраховаться» альтернативными технологиями? А последующий спад не означает ли, что вопросы газификации для России все-таки остаются на сегодняшний день неактуальными?

Таким образом, используя библиометрические инструменты для исследования динамики публикаций, связанных с технологией газификации, можно сделать однозначный вывод о неравномерности интереса в разных странах и регионах. Однако, несмотря на мнение одних экспертов о том, что эта технология является «технологией смутного времени», признания других исследователей о туманности перспектив для развития технологии газификации в нашей стране [5], публикационная картина показывает возросший интерес в этой теме именно в последние годы и в странах, неуклонно диверсифицирующих энергетику во всех секторах экономики и социальной жизни. Однако, возрастание интереса не относится к экономикам США и Канады. Это может означать, что «смутные времена» из экономики США и Канады уходят, и есть другие, помимо газификации биомассы, резервы обеспечения экономики энергией, тогда как страны ЕС все еще живут в состоянии «кризиса» экономики и необходимости искать альтернативу природным ресурсам именно в технологиях газификации. Что касается России и стран СНГ, динамика интереса к теме исследования (в части зарегистрированных патентов) органично ложится на кривую периодов войн, послевоенного строительства, застоя, перестройки и экономических кризисов.

К сожалению, отечественная статистика не дает нам полного представления об исследованиях российских ученых. Аналитическая система РИНЦ, существующая в России около 10 лет, еще не в состоянии отразить и «обработать» все публикации специалистов, глубина архива пока недостаточна для представительной выборки и не позволяет делать окончательные выводы о состоянии дел в какой-либо отрасли науки, в данном случае в газификации. Оставаясь достаточно прикладной наукой, сама газификация биомасс до сих пор не имеет четкого понятийного аппарата, отсутствует единая система ключевых слов, что затрудняет поиск материалов. Но, главное, 
отсутствие культуры оформления материалов в соответствии с правилами принятыми в мировой научной публикационной практике сказывается и на культуре оформления статей в отечественных «замкнутых» изданиях таким образом, что этих публикаций "не видит" сама система индексирования. Соответственно, результаты индексирования применительно к России пока не совсем адекватно отражают реальный интерес к одной из технологий динамично развивающейся биоэнергетики - газификации биомассы.

\section{Список использованных источников:}

1. Игра в цыфирь, или как теперь оценивают труд ученого (сборник статей о библиометрике). - М.: МЦНМО, 2011. - 72 с.:ил.

2. Коваленко, Г.В. Коммерциализация научно-технического потенциала газогенерации за рубежом и ее перспективы в России. // Леспроминформ. 2013. N. 3 (93). - C. 168-170.

3. Коваленко, Г.В. О факторах развития газификации древесины как технологии «смутного времени» // ISJ Theoretical \& Appled Science. - 2014. - № 1 (19). - C. 106-109.

4. Коваленко Г.В. Современное решение научных проблем и внедрение инноваций в целлюлозно-бумажную промышленность России / Г.В.Коваленко, М.В.Коваленко, Д.Д.Чуйко // Целлюлоза. Бумага. Картон. - 2012. - № 5. - С.3841

5. Копытов, В.В. Газификация конденсированных топлив. - М.: Инфра-Инженерия, 2012. $-504 \mathrm{c}$.

6. Малицкий Б. Наукометрия: новые функции и проблемы адекватности / Б.Малицкий, В.Рыбачук, А.Попович, А.Корецкий // Наука и инновации. - 2-13. № 1(119). - С. 11-17.

7. Маршакова, И. В. Система цитирования научной литературы как средство слежения за развитием науки. М.: Наука, - 1988. - 288 с.

8. Писляков, В.В. Методы оценки научного знания по показателям цитирования // Социологический журнал. - 2007. - № 1. - С. 128-140.

9. Проблемы наукометрии: состояние и перспективы развития: сб. тезисов докладов Международной научной конференции, Москва, 10-12 октября 2013 г./ Институт проблем развития науки РАН. М. : ИПРАН РАН, - 2013. - 124 с.

10. Шарабичев, Ю. Продуктивность ученых: инструменты оценки // Наука и инновации. - 2-13. -№ 1(119). - С.4-7. 